\title{
GODAE OCEANVIEW: FROM AN EXPERIMENT TOWARDS A LONG-TERM INTERNATIONAL OCEAN ANALYSIS AND FORECASTING PROGRAM
}

\author{
P.Y. Le Traon ${ }^{(1)}$, M. Bell $^{(2)}$, E. Dombrowsky ${ }^{(3)}$, A. Schiller ${ }^{(4)}$, K. Wilmer-Becker ${ }^{(2)}$ \\ With contributions from the International GODAE and GODAE OceanView science team
}

${ }^{(1)}$ IFREMER (French Institute for exploitation of the sea/Institut Français de Recherche pour l'Exploitation de la Mer), Centre de Brest, BP 70, 29280 Plouzané, France, Email: pierre.yves.le.traon@ifremer.fr

${ }^{(2)}$ Met Office, FitzRoy Road, Exeter EX1 3PB, UK, Email: mike.bell@metoffice.gov.uk;

kirsten.wilmer-becke@metoffice.gov.uk

${ }^{(3)}$ Mercator Océan, 8-10 rue Hermès, 31520 Ramonville, St-Agne, France Email: eric.dombrowsky@mercator-ocean.fr

(4) CAWCR-CSIRO (Centre for Australian Weather and Climate Research-Commonwealth Scientific and Industrial Research Organisation), GPO Box 1538, Hobart, Tasmania 7001, Australia Email: andreas.schiller@csiro.au

\begin{abstract}
Over the past 10 years, GODAE (Global Ocean Data Assimilation Experiment) through its International GODAE Steering Team (IGST) has coordinated and facilitated the development of global and regional ocean forecasting systems and has made excellent progress. GODAE as an experiment has ended in 2008. Its final symposium (Nice, November 12-15, 2008) allowed us to review the key achievements of the last 10 years and to discuss the future of operational ocean analysis and forecasting and proposals for its international coordination (GODAE Final Symposium Proceedings, $\left.2009^{[1]}\right)$. Main issues are summarized hereafter.
\end{abstract}

Although there are still major challenges to face, global operational oceanography now needs to transition from a demonstration to a permanent and sustained capability. Most GODAE groups have or are now transitioning towards operational or pre-operational status. GODAE systems are also evolving to satisfy new requirements (e.g. for coastal zone and ecosystem monitoring and forecasting, climate monitoring) and must benefit from scientific advances in ocean modeling and data assimilation. In order to ensure the required long-term international collaboration and cooperation on these issues, an international program on ocean analysis and forecasting systems called GODAE OceanView has been set up. Through its science team, GODAE OceanView will provide international coordination and leadership in:

- The consolidation and improvement of global and regional analysis and forecasting systems (physics)

- The progressive development and scientific testing of the next generation of systems covering biogeochemical and eco-systems and extending from the open ocean into the shelf sea and coastal waters.
- The exploitation of this capability in other applications (weather forecasting, seasonal and decadal prediction, climate change detection and its coastal impacts, etc).

- The assessment of the contribution of the various components of the observing system and scientific guidance for improved design and implementation of the ocean observing system. This is of particular relevance to OceanObs09.

The GODAE OceanView science team (GOVST) will provide a forum where the main operational and research institutions involved in global ocean analysis and forecasting can develop collaborations and international coordination of their activities. It will include scientists from the main operational systems, scientific experts with expertise in specific fields (e.g. observation, modeling and data assimilation) and representatives of key observing systems. Its core activity is related to modeling and data assimilation. Some of the GODAE OceanView objectives will be pursued through a series of Task Teams (e.g. Intercomparison and Validation, Observing System Evaluation, Coastal Ocean and Shelf Seas, Marine Ecosystem Monitoring and Prediction, etc). These teams will address specific topics that require active collaboration with international research programs (e.g. OOPC (Ocean Observations Panel for Climate), CLIVAR (Climate Variability and Predictability), IMBER (Integrated Marine Biogeochemistry and Ecosystem Research), and WCRP (World Climate Research Program)). Operational aspects related to product harmonization and standardization and links with JCOMM (Joint Technical Commission for Oceanography and Marine Meteorology) will be established through the JCOMM ET-OOFS (Expert Team for Operational Ocean Forecast Systems). 
Key words: analysis, forecasting, operational oceanography, organisation, international coordination.

\section{INTRODUCTION}

GODAE was set up in 1997 with the aim of demonstrating the feasibility and utility of global ocean monitoring and forecasting and to assist in building the infrastructure for global operational oceanography (Smith and Lefebvre, $1997^{[2]}$; GODAE Strategic Plan, $2001^{[3]}$ ). Over the past 10 years, GODAE has had a major impact on the development of global operational oceanography capability. Global modeling and data assimilation systems have been progressively developed, implemented and inter-compared. In-situ and remote sensing data are now routinely assimilated in global and regional ocean models to provide an integrated description of the ocean state. Observation, analysis and forecast products are readily accessible through major data and product servers. There has been increased attention to development of products and services and the demonstration of their utility for applications such as marine environment monitoring, weather forecasting, seasonal \& climate prediction, ocean research, maritime safety and pollution forecasting, national security, the oil \& gas industry, fisheries management and coastal and shelf-sea forecasting.

Over the last 10 years, the International GODAE Steering Team (IGST) has been responsible for the execution of GODAE. The inescapable need for multinational support for the required operational observing system, gave rise to a group strongly motivated to accelerate international progress through improved coordination, collaboration and sharing of real-time information, scientific knowledge and results. (Bell et. al, 2009 $\left.{ }^{[4]}\right)$

GODAE as an experiment ended in 2008 having achieved most of its goals. It has been demonstrated that global ocean data assimilation is feasible and GODAE has made important contributions to the establishment of an effective and efficient infrastructure for global operational oceanography that includes the required observing systems, data assembly and processing centers, modeling and data assimilation centers and data and product servers.

Although there are still major challenges to face (sustaining the global ocean observing system being an obvious one), global operational oceanography now needs to transition from a demonstration to a permanent and sustained capability. Operational ${ }^{1}$ data and products

\footnotetext{
${ }^{1}$ Following the GODAE Strategic Plan (2001), "operational" is used here "whenever the processing is done in a routine and regular way, with a pre-determined systematic approach and constant monitoring
}

are needed for most applications as well as for climate research. This is critical for applications, which cannot develop without operational services. In parallel, continuous improvements of operational oceanography systems are needed to satisfy new requirements (e.g. for coastal zone and ecosystem monitoring and forecasting, climate monitoring).

Most GODAE groups have or are now transitioning towards operational or pre-operational status. GODAE systems are also evolving to satisfy new requirements just mentioned and must benefit from scientific advances in ocean modeling and data assimilation. International collaboration and coordination of both operational and research activities related to ocean analysis and forecasting must continue during this sustained operational phase. The challenges and expectations are very demanding and can only be achieved through international collaboration.

This paper first provides a summary of GODAE achievements by referring to papers presented at the GODAE final symposium and in the GODAE Oceanography Special Issue. Then it discusses the organization for the new, sustained phase of GODAE, so called GODAE OceanView, first outlining the opportunities and challenges for operational oceanography in the next 10 years and secondly proposing a framework for the GODAE OceanView Science Team (GOVST) covering its objectives, relationships with other groups including parent bodies, main activities and task teams, terms of reference and links with JCOMM ET-OOFS.

\section{SUMMARY OF GODAE ACHIEVEMENTS}

The flow diagram of the functional components of GODAE (Fig. 1) captures the main sources of inputs required by GODAE, the data and product servers, the assimilation centres and the users of the outputs. It captures many of the interactions required to ensure or enhance the quality of the systems and their outputs and provides a suitable structure with which to explain the relationships between the final symposium papers and GODAE as a whole and the content of each paper.

The measurement network and data assembly and processing centres provide the main inputs to the assimilation centres (top centre and right of Fig. 1). Clark \& Wilson et al. (2009) ${ }^{[5]}$ provide a concise overview of the in situ and satellite components of the current global observing system and discuss the continuing work required to sustain it. Roemmich et al. $(2009)^{[6]}$ describe the realisation of the network of 3000

of performance. With this terminology, regular re-analyses may be considered as operational systems, as may be organized analyses and assessment of climate data". 
Argo floats freely reporting temperature and salinity profiles to $2000 \mathrm{~m}$ depth in a timely fashion, which has transformed the in situ profiler network. Donlon et al. $(2009)^{[7]}$ describe how the GHRSST (Global High Resolution Sea Surface Temperature) project has resulted in a coordinated network of centres disseminating SST (Sea Surface Temperature) data in real-time in a common format to agreed standards from a wide range of microwave and infra-red instruments on polar orbiting and geostationary satellites. Le Traon et al. (2009) ${ }^{[8]}$ summarise the substantial achievements during GODAE in the assembly and processing of observational data and the joint use of in situ and satellite data. Several assimilation centres have also developed useful tools for monitoring the input data on which their systems rely.

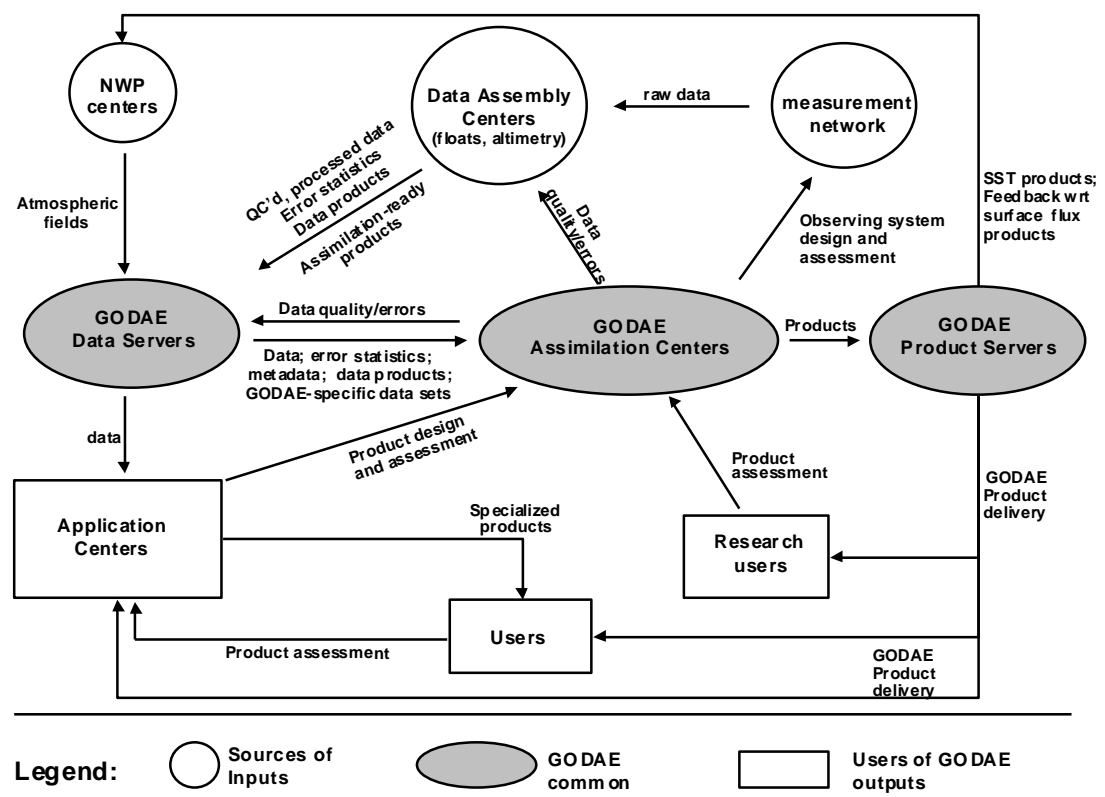

Figure 1: Diagram of the functional components of GODAE

Blower et al. (2009) ${ }^{[9]}$ describe the progress in the capabilities of data and product servers (see left of middle row o Fig. 1). They provide an overview of the underpinning concepts and technologies, which enable the GODAE data to be discovered, visualised, downloaded, intercompared and analysed all over the world. Progress within the assimilation centres (the central item in Fig. 1) is described in a number of papers. The tables and descriptions in Dombrowsky et al. $(2009)^{[10]}$ provide a useful overview of the present modelling and assimilation components of the major systems involved in GODAE. Most centres now: operate systems with $1 / 10^{\circ}$ or finer horizontal grid spacing; have a global capability; make use of community ocean models (e.g. HYCOM (HYbrid Coordinate Ocean Model), MOM4 (Modular Ocean Model) or NEMO (Nucleus for European Modelling of the Ocean); and assimilate in situ profile data, altimeter data and some form of surface temperature data. Cummings et al. (2009) ${ }^{[11]}$ provide some insight into the data assimilation schemes used in the various systems focusing on some practical aspects of the implementation and the way the covariances of forecast errors are calculated. They also provide some illustrations of the performance of the assimilation systems. Hurlburt et al. (2009) ${ }^{[12]}$ illustrate the skill of the high-resolution systems in forecasting sea surface height out to about a month ahead, sea surface currents, sea surface temperature and baroclinic coastally trapped waves. Their Fig. 5, comparing the statistics of forecasts of surface height for one of the systems with those of persistence for various regions, is a particularly interesting demonstration of forecast skill.

Product assessments and interactions with research users (lower right area of Fig. 1) have been key activities particularly in the last few years of GODAE. Hernandez et al. (2009) ${ }^{[13]}$ describe the procedures developed during GODAE to intercompare forecasts produced by different centres and illustrate the insights these can give into the performance of the systems. Lee et al. (2009) ${ }^{[14]}$ describe some examples of how systems developed for ocean state estimation have been used for climate research and how intercomparisons of results from the systems are being used to assess the consistency and uncertainty of the state estimates.

Three GODAE task teams were set up in 2006/2007. Oke et al. (2009) ${ }^{[15]}$ summarise results gathered by the observing system evaluation task team and outline the exciting prospects for future work. Their Fig. 2, illustrating the complementarity of the SST, altimeter 
and profile data for mesoscale prediction, and Table 2, which presents statistics on the dependence of the accuracy of 7-day forecasts, real-time analyses and delayed mode analyses on the availability of altimeter data, are particularly noteworthy illustrations and demonstrations of capability. De Mey et al. (2009) ${ }^{[16]}$ summarise the wide-ranging investigations discussed in the task team on the applications of GODAE for coastal modelling. Finally, Brasseur et al. (2009) ${ }^{[17]}$ outline a number of categories of potential ecological and biogeochemical applications and discuss the challenges this area poses to the fidelity of the physical models and assimilation schemes and to the measurement technologies.

The lower left part of Fig. 1 depicts the information flows to application centres (also known as downstream services) and users. Development of relevant enabling links was the focus of the Second GODAE Symposium 2004. Hackett et al. (2009) ${ }^{[18]}$ describe the use of GODAE outputs in monitoring and prediction of marine pollution (such as oil spills) and the main conclusions from a number of case studies. Davidson et al. $(2009)^{[19]}$ summarise demonstrations of the value of GODAE forecasts for safety and effectiveness of operations at Sea. Jacobs et al. (2009) ${ }^{[20]}$ provide examples of the wide variety of information and tactical decision aids generated using GODAE products to assist Naval operations. Finally, two papers illustrate the value of ocean monitoring and prediction for weather prediction. Goni et al. (2009) ${ }^{[21]}$ summarise the current operational use of upper ocean heat content information to forecast the intensity of tropical cyclones and current research in this area. Balmaseda et al. (2009) ${ }^{[22]}$ summarise the advances over the last decade in ocean initialisation of coupled forecast systems and their impact on ocean state estimates and seasonal forecasts.

In summary, the papers published in the GODAE Symposium proceedings provide a very informative overview of the substantial processing capabilities that have been developed over the last 10 years for real-time and robust collection and processing of measurements and generation of analyses and forecasts, and the dissemination and scientific assessment of these products. They demonstrate that forecasting of open ocean mesoscale phenomena is feasible, at least in many regions. They also show that the forecasts are useful for some applications (e.g. heat content for tropical cyclones) whilst for other applications the level of forecast skill achieved so far is quite limiting (e.g. use of surface currents for open ocean oil spill forecasting) and as a result a high level of expertise is required to make use of them.

\section{ASSESSMENT OF THE GODAE COORDINATION}

GODAE was very successful in building an active international working-level community. This section aims to identify elements, which were key to achieving this, that should if possible be captured in future coordination. In addition to these positive lessons learnt, we identify some of the problems and difficulties which future coordination should anticipate.

The first of the success factors in the coordination of GODAE was that it captured the imagination and interest of the key groups and individuals at working level that were best placed to contribute to it. More specifically:

- GODAE had an inspiring rationale, vision and leadership

- the birth of Argo made the experiment plausible

- the GODAE proposal generated a sense of purpose and excitement at working level

- the GODAE proposal provided confidence to invest at the national programme and individual career levels

A second factor in the success of the coordination of GODAE was its ambitious and inclusive nature. The discussions of the GODAE common in the first half of GODAE stimulated:

- collaboration between the operational and research communities with far reaching consequences (e.g. MERSEA (Marine Environment and Security for the European Area), MyOcean consortia)

- an open data policy

- intercomparisons of analyses and forecasts

- sharing of expertise and experience in the development of models, diagnosis of errors, demonstrations of utility and the role of intermediate service providers

- the use of modern methods (for example modern web servers and ensemble techniques for calculation of error covariances)

GODAE also had a clear set of objectives and a timetable for implementation. Calculated risks were taken to explore ambitious options whilst at the same time being mindful of the objectives and timetable. 
A third success factor in GODAE's coordination was that the meetings and events that were organised were highly valued by the participants. The characteristics of the IGST, which appear to have contributed particularly to this, are that:

- the scientific and technical experts were put in charge of the experiment

- there was a specific focus on scientific advances for operational application (which was the main interest of most participants)

- there were clear and ambitious but achievable objectives

- the meetings were truly global and of international scope (so were distinctive from other meetings)

- the meetings included constructive and refreshing specialist discussions

- the interest and guidance of the Patrons was helpful and supportive

Furthermore, the GODAE Summer School and the First Symposium provided some excellent review articles and summaries, which provided very helpful introductions to newcomers to the field. The Second Symposium also enabled a very valuable exchange of information, experience and views on developing downstream services.

As mentioned at the start of this section there were a number of interconnected difficulties, which made GODAE harder than, may have been foreseen and which will also be issues for future coordination:

- development of good quality assimilation systems and forecasts took longer than expected

- engaging the interest of downstream users was harder than anticipated

- funding for Argo and altimetry is still not secure

The resources available did not always match the ambition. Many national teams' resources were limited or delayed and most IGST members were unable to fit their IGST commitments into their day-jobs. There was a heavy reliance on a few key people (e.g. Christian le Provost, Neville Smith, Michele Rienecker) whose contributions could not be replaced when they left the team. Pro-active coordination from the Project Office started late.

\section{OPERATIONAL OCEANOGRAPHY: CHALLENGES FOR THE NEXT DECADE}

While most operational oceanography systems developed during GODAE are transitioning to preoperational or operational status, they are facing new expectations and requirements and are extending or will have to extend their capabilities. There are also important issues related to ocean observing system (sustainability, evaluation and evolution). These main challenges and opportunities for the next decade are summarized below:

\subsection{New societal needs}

During the last decade, new pressing societal issues to which ocean analysis and forecasting can make substantial contributions have evolved. They are now quite diverse and are not limited to open ocean forecasts (although open ocean forecasts will continue to serve major applications areas). The most important are:

- The use of data assimilation to provide integrated descriptions of the global ocean state (reanalyses) and to characterize and detect climate change in the ocean;

- The application of ocean prediction techniques to the prediction of climate change (so-called decadal prediction);

- The assessment and characterization of specific sources of uncertainty in down-scaling of climate and climate-change scenario simulations and predictions in studies of the impact of climate change in coastal regions (e.g. extreme events, flooding, ecosystems, ...);

- The development of improved atmospheric and climate forecasts (near coasts, hurricanes/tropical cyclones, monsoons, seasonal);

- Real-time forecasting in near-shore / coastal waters (physics, biogeochemical and ecosystems...) and coupling between open ocean and coastal areas;

- Ecosystem modelling and the development of ecosystem based management of marine resources (influence of physical transports and processes on marine life, modeling up to high trophic levels); 
- Marine environment monitoring in support of policies (e.g. European Marine Strategy).

\subsection{Improving and extending capabilities of operational oceanography systems}

Continuous improvement of operational oceanography systems and the development of new capability are needed to address these new societal needs. This demands state-of-the art research leadership and calls for dedicated cooperation with international WCRP, IGBP (International Geosphere-Biosphere Programme) and SCOR (Scientific Committee on Oceanic Research) research programs such as CLIVAR, GEOTRACE, SOLAS (Surface Ocean - Lower Atmosphere Study) and IMBER.

Schiller et al. (2009) ${ }^{[23]}$ lists the main research topics that operational oceanography faces: high-resolution physical modeling, downscaling, biogeochemical and ecosystem modelling, ocean/wave/atmosphere coupling, data assimilation and coupled data assimilation, error estimates, long-term reanalyses, use of new observations. What major developments can we expect to see in the next ten years? Current trends suggest advances in physical oceanography associated with a maturing of the eddy-resolving dataassimilating models, and a stronger integration into coupled NWP (Numerical Weather Prediction) and climate modelling. There are still some significant challenges in the data-assimilation techniques themselves, and one can expect to see significant improvement there. At the same time, the user community is looking to extend these models inshore, across the shelf, and even into bays and estuaries. Better methods for nesting models, or for variable resolution and adaptive model grids, are likely to emerge. We can expect to see improved integration of wave models into coastal coupled atmospherichydrodynamic models, and improved sediment model predictions of turbidity and coastal geomorphology. This will be partly driven by concern about effects of increased sea level and storm frequency / intensity. The extension of data-assimilating models inshore assumes that we can develop coastal observing systems to support them. The challenge will be to develop cost-effective in-situ coastal observing systems. Physical observing systems at basin scale are likely to face the challenge to maintain the current density of Argo and satellite altimeters. It is also likely that deployment of smart tags on pelagic animals will increase. For chemistry and biology, there do seem to be prospects for significant advances in observations at the basin scale over the next five years. We can expect to see further integration of biogeochemical models with ecosystem models, one of the very objectives of the IMBER research program.

\subsection{Global and regional ocean observing system}

Over the last 10 years, a global ocean observing system (in situ and remote sensing) has been progressively implemented. The system, primarily designed to serve climate research, is used as a backbone for most operational oceanography applications. Although significant progress has been made, (e.g. Argo and Jason are outstanding successes), sustaining the global ocean observing system remains a challenging task. There is also a pressing need to develop further regional and coastal components and, as discussed above, to extend the measurement capabilities to biogeochemical parameters. This endeavor is clearly beyond the scope of ocean analysis and forecasting teams and involves major international or intergovernmental organizations (e.g. WMO (World Meteorological Organization) and IOC (International Oceanographic Commission) through JCOMM, GOOS (Global Ocean Observing System) and GCOS (Global Climate Observing System), GEO (Group on Earth Observations), CEOS (Committee on Earth Observing Satellites)) and research programs (e.g. WCRP and IGBP). Ocean analysis and forecasting systems are, however, an appropriate and powerful means to assess the impact of the observing system, to identify gaps and to improve the efficiency/effectiveness of the observing system. Through the development of applications and users links, these systems are also essential in contributing to the long-term sustainability of the ocean observing system. Collaboration between ocean analysis and forecasting teams on ocean observing system issues is thus highly desirable. It would organize the feedback towards ocean observing system agencies (space, insitu) and would provide sound and robust recommendations and guidance for the evolution of the global ocean observing system. It would also help to better demonstrate its value and effectiveness.

\section{GODAE OCEANVIEW: OBJECTIVES AND INTERNATIONAL ORGANIZATION}

\subsection{Objectives}

The GODAE OceanView Science Team (GOVST) has been created, with the mission to define, monitor, and promote actions aimed at coordinating and integrating research associated with multi-scale and multidisciplinary ocean analysis and forecasting systems, thus enhancing the value of GODAE OceanView outputs for research and applications. Over the next decade, the science team will provide international coordination and leadership in:

- The consolidation and improvement of global and regional analysis and forecasting systems (physics). 
- The progressive development and scientific testing of the next generation of ocean analysis and forecasting systems, covering bio-geochemical and eco-systems as well as physical oceanography, and extending from the open ocean into the shelf sea and coastal waters.

- The exploitation of this capability in other applications (weather forecasting, seasonal and decadal prediction, climate change detection and its coastal impacts, etc).

- The assessment of the contribution of the various components of the observing system and scientific guidance for improved design and implementation of the ocean observing system.

It is envisaged that the GOVST will coordinate a program of activities implemented through the nationally funded activities of its members.

\subsection{Internal organisation and relationships with other groups}

The GOVST will provide a forum where the main operational and research institutions (national groups) involved in global ocean analysis and forecasting can develop collaborations and international coordination of their activities. The primary purpose of the team is to accelerate the improvement and exploitation of these systems through exchange of information and expertise and the coordination of joint assessments. The scientists leading the scientific development of the major systems for generating ocean hindcasts and real-time operational ocean forecasts will constitute an inner core of the GOVST. The science team will also include scientists from the main operational systems, scientific experts with expertise in specific fields (e.g. observation, modeling, data assimilation) and representatives of key observing systems (e.g. from the Argo, GHRSST and OST science teams).

Members of GODAE OceanView will adhere to the same principles of free, open and timely exchange of data and products, sharing of scientific results and experience developing applications, which were important factors in the success of GODAE.

The societal benefits from these systems will only be realised through joint work with other teams of experts. Potential benefits include improvements in the day-today management of coastal waters, the management of marine ecosystems, weather prediction from hours to decades ahead, and the expected impacts of climate change on the oceans and coastal waters.

These benefits and the GODAE OceanView systems themselves are critically dependent on both the satellite and in situ components of the Global Ocean Observing
System (GOOS). Through the development of improved Observing System Evaluations (OSEs) GODAE OceanView contributes to coherent, effective and scientifically robust advocacy of the case for and prioritisation of the components of the GOOS.

The hindcast and forecast systems developed by the GOVST members both require inputs from and should be a valuable resource for the oceanographic research community. Support for cooperation between research and operational groups is a key element of GODAE OceanView.

The GOVST will need to develop linkages with other groups and report on its progresses, achievements and recommendations. GODAE OceanView will informally report to JCOMM and will have strong links with JCOMM ET-OOFS. It will develop linkages with GOOS, OOPC, PICO (Panel for Integrated Coastal Observations), IOC, CAS-WGNE (Commission for Atmospheric Sciences - Working Group on Numerical Experimentation), WCRP and CEOS.

Some of the GODAE OceanView objectives will be pursued through a number of Task Teams. These teams will address specific topics of particular importance to GODAE OceanView in collaboration with other groups and international research programs (e.g. OOPC, CLIVAR and IMBER).

Operational aspects related to product harmonization and standardization and links with JCOMM will be established through the JCOMM ET-OOFS.

A GODAE OceanView program office with one permanent member of staff will provide assistance to the science team. In addition, a Patrons group consisting of individuals who are well placed to commit resources to support the GODAE OceanView program will be set up to provide advice and guidance to the science team. This group will include program managers from the national operational systems and representatives from the space agencies and the institutions to which GODAE OceanView reports. The members of this group will be expected to provide regular subscriptions to support the funding of the GODAE OceanView program office.

\subsection{Main activities and task teams}

GODAE OceanView will undertake activities which:

- foster and coordinate the development of new ocean monitoring, modeling and assimilation systems for ocean forecasting both for operational and for research applications with the goal of improved accuracy and utility of ocean analysis and forecasting products; 
- $\quad$ promote access to data and information products and enhanced uptake of ocean analysis and forecasting products with governments, the public and private sectors;

- support the transition from the demonstration of new services based on ocean forecasting to the provision of timely, robust and reliable operational services. The Science Team will report to JCOMM ET-OOFS on relevant scientific developments whilst JCOMM ET-OOFS will make recommendations to the Science Team on what improvements would be most useful to users.

- demonstrate the value of ocean observing systems, in order to ensure access to a sustained real-time and high-quality ocean observing system, and liaise with major observing system programs (e.g. OOPC, CEOS, GOOS, GCOS) and science teams (e.g. Argo, Ocean Surface Topography, GHRSST) on observing system issues. In particular, the science team will collaborate with the Argo Science Team on the evolution of the global Argo array (e.g. sampling, data \& products, biogeochemical measurements, deeper measurements).

- coordinate the development of new capabilities, in cooperation with other relevant international research programs, through a number of task teams.

The initial list of GODAE OceanView Task Teams will include:

\subsubsection{Intercomparison and Validation Task Team}

The team will pursue activities developed during GODAE. It will coordinate and promote the development of scientific validation and intercomparison of operational oceanography systems. Activities will include the definition of metrics to assess the quality of analyses and forecasts (e.g. forecast skills) both for physical and biogeochemical parameters and the setting up of specific global and regional intercomparison experiments. Metrics related to specific applications will also be defined. The team will liaise with the JCOMM ET-OOFS team for operational implementation. It will develop cooperation with CLIVAR/GSOP (Global Synthesis and Observations Panel) for climate issues.

\subsubsection{Observing System Evaluation Task Team}

One of the aims of GODAE OceanView is to formulate more specific requirements for observations on the basis of improved understanding of data utility. The team is jointly formed by GODAE OceanView and OOPC. Through the task team, GODAE OceanView and OOPC partners will get organized at the international level to provide consistent and scientifically justified responses to agencies and organizations in charge of sustaining the global and regional ocean observing systems used for ocean monitoring and forecasting at short-range, seasonal and decadal time-scales. This activity will require harmonized protocols for observation impact assessment [e.g. Observing System Evaluation (OSEs) and Observing System Simulation Experiments (OSSE)], tools for routine production of appropriate diagnostics using NWP-derived methods, common sets of metrics for intercomparison of results, and objective methodologies which can be used to provide recommendations to the appropriate agencies and organizations. In the longer term, consideration will need to be given to an evaluation strategy for identifying observing system requirements for different, possibly user-specific, applications. The Task Team will develop its international collaboration through regular meetings and workshops.

\subsubsection{Coastal Ocean and Shelf Seas Task Team}

This task team would deal with scientific issues in support of multidisciplinary analysis and forecasting of the coastal transition zone and shelf/open ocean exchanges in relation with the larger-scale efforts. The specific objectives would include: (1) In the continuation of the GODAE CSSWG, discuss and promote the uses of GODAE OceanView products and results for coastal ocean forecasting systems and for coastal applications in a wider community. (2) Discuss and foster integration of the varied routine sources of information in coastal ocean forecasting systems: largescale forecasts, satellite observations, coastal observatories, etc.; discuss and support the development of coastal observing systems in terms of science and technology. (3) Discuss the key physical and biogeochemical processes, which have the greatest impact on modeling and forecasting quality and their utility for applications; this includes validation and forecast verification. (4) Discuss and promote state-ofthe-art methodology such as two-way coupling, unstructured-grid modeling, downscaling, data assimilation, array design.

\subsubsection{Marine Ecosystem Monitoring and Prediction Task Team}

The integration of new models and assimilation components for ocean biogeochemistry and marine ecosystem monitoring and prediction will be required to bridge the gap between the current status of the GODAE capabilities and new applications in areas such as fisheries management, marine pollution and carbon cycle monitoring. Following the outcome of a first IMBER-GODAE working group established in 2007, the Task Team will be set up with the goal to define, promote and coordinate actions between developers of operational systems and ecosystem modeling experts, in tight connection with IMBER. The objectives of the task team will be (i) to design appropriate ecosystem 
modeling and assimilation strategies that will be compatible with the functionalities of operational systems; (ii) to develop numerical experiments aimed at improving, assessing and demonstrating the value of operational products for marine ecosystem monitoring and prediction; (iii) to expand the concept of the "GODAE metrics" to biogeochemical variables and to coordinate intercomparison exercises across international groups to assess implementation progress and performances; (iv) to identify the essential sets of physical and biogeochemical observations required to constrain the coupled models and to formulate relevant recommendations to further develop the global ocean observing system; (v) to promote and organize educational activities (summer schools, training workshops, etc.) aimed at sharing experience between young scientists, operational oceanographers and marine ecosystem experts. In addition to the link with IMBER, the task team will articulate its activities with other relevant international programs such as GEOTRACES and SOLAS.

In addition, GODAE OceanView will continue and strengthen its collaboration with CLIVAR/GSOP on global ocean synthesis activities. Other task teams may be formed during the course of GODAE OceanView (e.g. links with NWP through CAS).

\subsection{Links with the JCOMM ET-OOFS}

As GODAE prototype systems transition to operational systems, international collaboration on product standardization and interoperability between systems must be maintained and developed. The joint WMO/IOC Technical Commission JCOMM provides an appropriate intergovernmental mechanism for the coordinating role and has recently established an expert team on operational oceanographic forecasting systems (ET-OOFS) within its Services Program Area for this purpose. Terms of reference of the ET-OOFS are as follows:

- Develop and maintain "The Guide to Operational Oceanographic Forecasting systems of the World"

- Provide advice to JCOMM teams and member states on the application, nomenclature, symbology and standards used by operational ocean forecasting systems;

- Develop and operate an inter-comparison framework for near real time monitoring of OOFS outputs building on the legacy of GODAE;

- Work effectively with the Scientific community developing and maintaining OOFS

- Provide observation requirements for OOFS to the JCOMM Observations Program Area;
- Provide advice to the JCOMM Data Management Program Areas;

- Provide advice to Members/Member States on operational Ocean Forecast systems.

The GODAE OceanView Science Team will report to ET-OOFS on scientific and operational developments, while ET-OOFS will provide recommendations on service provision (for instance standardization) based on users' needs. The Intercomparison and Validation Task Team will provide inputs and recommendations to the ET-OOFS on standardization of validation activities (e.g. a minimum set of metrics that should be implemented in operational systems to monitor the quality of analyses and forecasts). We anticipate that the two groups (GOVST and ETOOFS) will work very closely in the coming years: the ET-OOFS chair will be de facto member of GODAE Ocean View science team; and GODAE OceanView systems will be represented in the ET-OOFS.

\section{CONCLUSIONS}

In summary:

- Operational Oceanography faces many challenges with time scales ranging from weather to climate

- It is inherently an international issue, requiring broad collaboration to span the global oceans; it is beyond the capability of any one country

- GODAE OceanView will promote the development of ocean modelling and assimilation in a consistent framework to optimize mutual progress and benefit

- It will promote the associated exploitation of improved ocean analyses and forecasts

- It will provide a means to assess the relative contributions of and requirements for observing systems, and their respective priorities

We believe the GODAE OceanView programme will result in the long-term international collaboration and cooperation required for the next, sustained, phase of operational oceanography. GODAE OceanView now needs to receive wide support from the international community and to better define its links with other international research programs. Based on these inputs, a work-plan for the next 4 years will be developed.

\section{ACKNOWLEDGEMENTS:}

This paper was written with many inputs from the GODAE International Science Team and Patrons group. 


\section{REFERENCES}

[1] GODAE final symposium proceedings (2009), The revolution in global ocean forecasting: GODAE 10 Years of achievements, online document (www.godae.org).

[2] Smith, N. and M. Lefebvre (1997). Monitoring the oceans in the 2000s: an integrated approach The Global Ocean Data Assimilation Experiment (GODAE). International Symposium, Biarritz.

[3] International GODAE Steering Team (2000). The Global Ocean Data Assimilation Experiment Strategic Plan, GODAE Report No. 6.

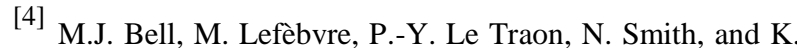
Wilmer-Becker. GODAE: The Global Ocean Data Assimilation Experiment. Oceanography Magazine, Special Issue on the Revolution of Global Ocean Forecasting GODAE: 10 Years of Achievement, Volume 22, Number 3.

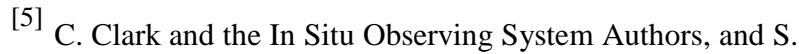
Wilson and the Satellite Observing System Authors. An Overview of Global Observing Systems relevant to GODAE. Oceanography Magazine, Special Issue on the Revolution of Global Ocean Forecasting - GODAE: 10 Years of Achievement, Volume 22, Number 3.

D. Roemmich and the Argo Steering Team. Argo: The Challenge of Continuing 10 Years of Progress. Oceanography Magazine, Special Issue on the Revolution of Global Ocean Forecasting - GODAE: 10 Years of Achievement, Volume 22, Number 3.

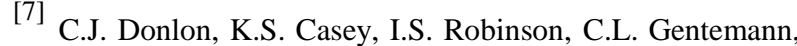
R.W. Reynolds, I. Barton, O. Arino, J. Stark, N. Rayner, P. LeBorgne, D. Poulter, J. Vazquez-Cuervo, E. Armstrong, H. Beggs, D. Llewellyn-Jones, P.J. Minnett, C.J. Merchant, and R. Evans. The GODAE High-Resolution Sea Surface Temperature Pilot Project. Oceanography Magazine, Special Issue on the Revolution of Global Ocean Forecasting GODAE: 10 Years of Achievement, Volume 22, Number 3.

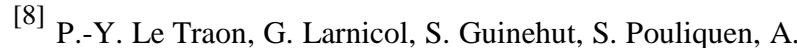
Bentamy, D. Roemmich, C. Donlon, H. Roquet, G. Jacobs, D. Griffin, F. Bonjean, N. Hoepffner, and L.-A. Breivik. Data Assembly and Processing For Operational Oceanography: 10 Years of Achievements. Oceanography Magazine, Special Issue on the Revolution of Global Ocean Forecasting GODAE: 10 Years of Achievement, Volume 22, Number 3.

[9] J.D. Blower, F. Blanc, M. Clancy, P. Cornillon, C. Donlon, P. Hacker, K. Haines, S.C. Hankin, T. Loubrieu, S. Pouliquen, M. Price, T.F. Pugh, and A. Srinivasan. Serving GODAE Data and Products to the Ocean Community. Oceanography Magazine, Special Issue on the Revolution of Global Ocean Forecasting - GODAE: 10 Years of Achievement, Volume 22, Number 3.
[10] E. Dombrowsky, L. Bertino, G.B. Brassington, E.P. Chassignet, F. Davidson, H.E. Hurlburt, M. Kamachi, T. Lee, M.J. Martin, S. Mei, and M. Tonani. GODAE Systems in Operation. Oceanography Magazine, Special Issue on the Revolution of Global Ocean Forecasting - GODAE: 10 Years of Achievement, Volume 22, Number 3.

[11] J. Cummings, L. Bertino, P. Brasseur, I. Fukumori, M. Kamachi, M.J. Martin, K. Mogensen, P. Oke, C.E. Testut, J. Verron, and A. Weaver. Ocean Data Assimilation Systems for GODAE. Oceanography Magazine, Special Issue on the Revolution of Global Ocean Forecasting - GODAE: 10 Years of Achievement, Volume 22, Number 3.

${ }^{[12]}$ H.E. Hurlburt, G.B. Brassington, Y. Drillet, M. Kamachi, M. Benkiran, R. Bourdallé-Badie, E.P. Chassignet, G.A. Jacobs, O. Le Galloudec, J.-M. Lellouche, E.J. Metzger, P.R. Oke, T.F. Pugh, A. Schiller, O.M. Smedstad, B. Tranchant, H. Tsujino, N. Usui, and A.J. Wallcraft. HighResolution Global and Basin-Scale Ocean Analyses and Forecasts. Oceanography Magazine, Special Issue on the Revolution of Global Ocean Forecasting - GODAE: 10 Years of Achievement, Volume 22, Number 3.

${ }^{[13]}$ F. Hernandez, L. Bertino, G. Brassington, E. Chassignet, J. Cummings, F. Davidson, M. Drévillon, G. Garric, M. Kamachi, J.-M. Lellouche, R. Mahdon, M.J. Martin, A. Ratsimandresy, and C. Regnier. Validation and Intercomparison Studies Within GODAE. Oceanography Magazine, Special Issue on the Revolution of Global Ocean Forecasting - GODAE: 10 Years of Achievement, Volume 22, Number 3.

${ }^{[14]}$ T. Lee, T. Awaji, M.A. Balmaseda, E. Greiner, and D. Stammer. Ocean State Estimation for Climate Research. Oceanography Magazine, Special Issue on the Revolution of Global Ocean Forecasting - GODAE: 10 Years of Achievement, Volume 22, Number 3.

[15] P.R. Oke, M.A. Balmaseda, M. Benkiran, J.A. Cummings, E. Dombrowsky, Y. Fujii, S. Guinehut, G. Larnicol, P.-Y. Le Traon and M.J. Martin. Observing System Evaluations Using GODAE Systems. Oceanography Magazine, Special Issue on the Revolution of Global Ocean Forecasting - GODAE: 10 Years of Achievement, Volume 22, Number 3.

${ }^{[16]}$ P. De Mey, P. Craig, F. Davidson, C.A. Edwards, Y. Ishikawa, J.C. Kindle, R. Proctor, K.R. Thompson, J. Zhu, and the GODAE Coastal and Shelf Seas Working Group (CSSWG) Community. Applications in Coastal Modeling and Forecasting. Oceanography Magazine, Special Issue on the Revolution of Global Ocean Forecasting - GODAE: 10 Years of Achievement, Volume 22, Number 3. 
${ }^{[17]}$ P. Brasseur, N. Gruber, R. Barciela, K. Brander, M. Doron, A. El Moussaoui, A.J. Hobday, M. Huret, A.-S. Kremeur, P. Lehodey, R. Matear, C. Moulin, R. Murtugudde, I. Senina, and E. Svendsen. Integrating Biogeochemistry and Ecology Into Ocean Data Assimilation Systems. Oceanography Magazine, Special Issue on the Revolution of Global Ocean Forecasting - GODAE: 10 Years of Achievement, Volume 22, Number 3.

${ }^{[18]}$ B. Hackett, E. Comerma, P. Daniel, and H. Ichikawa. Marine Oil Pollution Prediction. Oceanography Magazine, Special Issue on the Revolution of Global Ocean Forecasting GODAE: 10 Years of Achievement, Volume 22, Number 3.

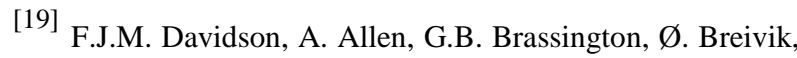
P. Daniel, M. Kamachi, S. Sato, B. King, F. Lefevre, M. Sutton, and H. Kaneko. Applications of GODAE Ocean Current Forecasts to Search and Rescue and Ship Routing. Oceanography Magazine, Special Issue on the Revolution of Global Ocean Forecasting - GODAE: 10 Years of Achievement, Volume 22, Number 3.

[20] G.A. Jacobs, R. Woodham, D. Jourdan, and J. Braithwaite. GODAE Applications Useful to Navies Throughout the World. Oceanography Magazine, Special Issue on the Revolution of Global Ocean Forecasting GODAE: 10 Years of Achievement, Volume 22, Number 3.

[21]

G. Goni, M. DeMaria, J. Knaff, C. Sampson, I. Ginis, F. Bringas, A. Mavume, C. Lauer, I.-I. Lin, M.M. Ali, P. Sandery, S. Ramos-Buarque, K. Kang, A. Mehra, E. Chassignet, and G. Halliwell. Applications of Satellite-Derived Ocean Measurements to Tropical Cyclone Intensity Forecasting. Oceanography Magazine, Special Issue on the Revolution of Global Ocean Forecasting - GODAE: 10 Years of Achievement, Volume 22, Number 3.

${ }^{[22]}$ M.A. Balmaseda, O.J. Alves, A. Arribas, T. Awaji, D.W. Behringer, N. Ferry, Y. Fujii, T. Lee, M. Rienecker, T. Rosati, and D. Stammer. Ocean Initialization for Seasonal Forecasts. Oceanography Magazine, Special Issue on the Revolution of Global Ocean Forecasting - GODAE: 10 Years of Achievement, Volume 22, Number 3.

Schiller, A., P. Brasseur, P. De Mey, R. Proctor and J. Verron: Key Future Research Priorities in Ocean Forecasting, The revolution in global ocean forecasting GODAE final symposium proceedings (2009): GODAE 10 Years of achievements. 